2017

\title{
Danger of Snow in the Sunshine State
}

Dmitrii Karpenko

University of South Florida

\section{Advisors:}

Arcadii Grinshpan, Mathematics and Statistics

Valerii Karpenko, Iceberg, LLC

Problem Suggested By: Dmitrii Karpenko

Follow this and additional works at: https://digitalcommons.usf.edu/ujmm

Part of the Mathematics Commons

UJMM is an open access journal, free to authors and readers, and relies on your support:

Donate Now

\section{Recommended Citation}

Karpenko, Dmitrii (2017) "Danger of Snow in the Sunshine State," Undergraduate Journal of Mathematical Modeling: One + Two: Vol. 7: Iss. 2, Article 2.

DOI: http://doi.org/10.5038/2326-3652.7.2.4877

Available at: https://digitalcommons.usf.edu/ujmm/vol7/iss $2 / 2$ 


\title{
Danger of Snow in the Sunshine State
}

\begin{abstract}
The main purpose of the project is to investigate the maximum deflection of a rectangular $16 \times 8$ inches beam, supported on both ends under uniform loading stress under snow pressure in the event that Tampa experiences snowfall. The required information for the project is the material of the beam and its dimensions, measurement of the area of the roof that would accumulate snow, and calculations of the Moment of Inertia and Uniform Distributed Load for the beam. The maximum deflection of the beam can be calculated using the information above.

The outcome of the research shows that the roof construction of the University of South Florida Marshall Student Center stage, can withstand all of Florida's potential weather conditions, even in rare weather cases like the snowfall of March 6, 1954 when Florida experienced 4 inches of snow. The maximum deflection of the beam in this case is $1.1 \mathrm{~cm}$, which is below the maximum allowable value of $3.0 \mathrm{~cm}$ for the $9.0 \mathrm{~m}$ spans according to AS 1170.1 Minimum design loads on structures.
\end{abstract}

\section{Keywords}

deflection, beam, load, snow

Creative Commons License

(c) (i) $(9)$

This work is licensed under a Creative Commons Attribution-Noncommercial-Share Alike 4.0 License. 


\section{PROBLEM STATEMENT}

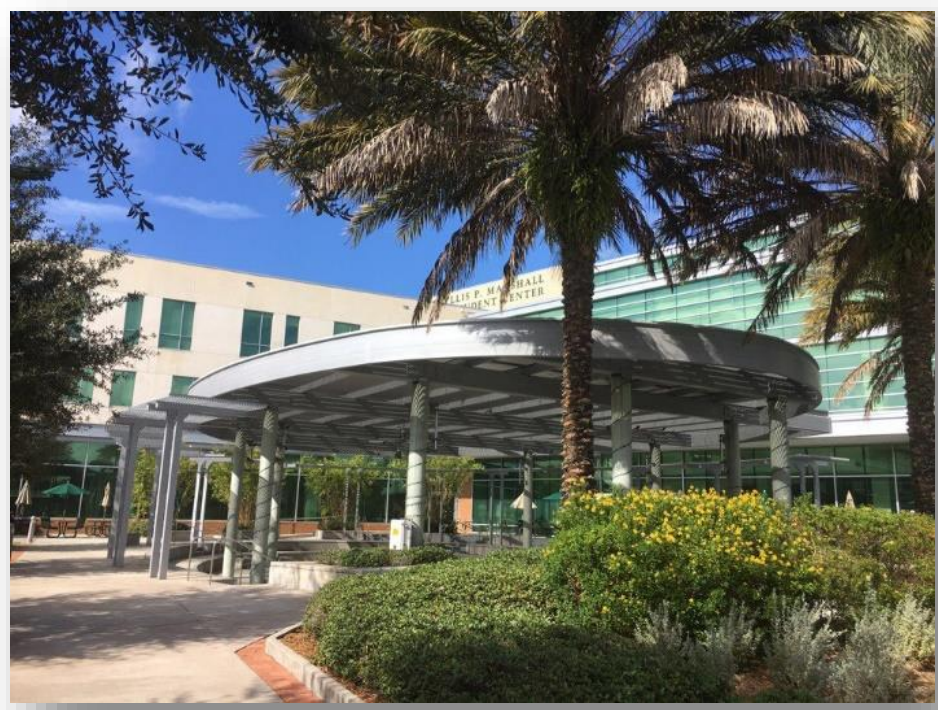

Picture 1: Photo of the stage at University of South Florida Marshall Student Center 2016.
The biggest snowfall in Florida occurred on March 6, 1954 when Florida experienced 4 inches of snow [5]. This event had been two years before the University of South Florida was founded. The calculation of maximum deflection of rectangular - $16 \times 8$ inches

beam should show whether the roof of the University of South Florida Marshall Student Center stage is ready for snow or not if Tampa experiences such snowfall again.

\section{MATHEMATICAL DESCRIPTION AND SOLUTION APPROACH}

\section{Young's Modulus $(E)$}

Young's Modulus or Modulus of Elasticity - is a measure of stiffness of an elastic material. It is used to describe the elastic properties of objects like wires, rods, or columns when they are stretched or compressed. In our case, it can be used to predict the elongation or compression of an object as long as the stress is less than the yield strength of the material [2].

Young's modulus can be expressed as: $\quad \boldsymbol{E}=\frac{|\boldsymbol{S T R E S S}|}{|\boldsymbol{S T R A I N |}|}$ 


\section{$\underline{\text { Stress }}$}

Stress is force per unit area and can be expressed as:

$$
\sigma=\frac{\mathrm{F}}{\mathrm{A}}
$$

Where:

$\boldsymbol{\sigma}=\operatorname{stress}\left(\mathrm{N} / \mathrm{m}^{2}\right)\left(\mathrm{lb} / \mathrm{in} \mathrm{n}^{2}, \mathrm{psi}\right)$

$\boldsymbol{F}=\operatorname{force}(N)(l b)$

$\boldsymbol{A}=$ area of object $\left(\mathrm{m}^{2}\right)\left(\mathrm{in}^{2}\right)$

- tensile stress - stress that tends to stretch or lengthen the material - acts normal to the stressed area

- compressive stress - stress that tends to compress or shorten the material - acts normal to the stressed area

- $\quad$ shearing stress - stress that tends to shear the material - acts in plane to the stressed area at right-angles to compressive or tensile stress [2]

\section{$\underline{\text { Strain }}$}

Strain is "deformation of a solid due to stress" - a change in dimension divided by the original value of the dimension - and can be expressed as:

$\varepsilon=\frac{\mathrm{dL}}{\mathrm{L}}$

Where:

$\varepsilon=\operatorname{strain}(\mathrm{m} / \mathrm{m})(\mathrm{in} / \mathrm{in})$

$\boldsymbol{d} \boldsymbol{L}=$ elongation or compression (offset) of the object $(m)($ in $)$

$\boldsymbol{L}=$ length of the object (m) (in) 
Modulus of Elasticity for a given material is a constant. Here is a table of Modulus of Elasticity for different materials [6]:

\begin{tabular}{|c|c|}
\hline Material & Modulus of Elasticity $(\mathbf{E})\left(\mathbf{1 0} \mathbf{~}^{\mathbf{N}} / \mathbf{m}^{\mathbf{2}}, \mathbf{G P a}\right)$ \\
\hline Aluminum & 69 \\
\hline Steel, Structural ASTM-A36 & $\mathbf{2 0 0}$ \\
\hline Sapphire & 435 \\
\hline
\end{tabular}

In this project we are interested in Modulus of Elasticity for the Steel, which is equal to $200 \mathrm{GPa}$ or $200000000000 \mathrm{~Pa}$ (Conversion into Pascal is important for the maximum deflection formula).

\section{MOMENT OF Inertia (I)}

Moment of inertia quantifies the resistance of a physical object to angular acceleration.

Moment of inertia is to rotational motion as mass is to linear motion.

Moment of inertia of hollow section can be found

by first calculating the inertia of a larger rectangle

and then by subtracting the hollow portion from this large rectangle [2].

Moment of Inertia about Y-axis:

$$
I_{y}=\frac{H B^{3}}{12}-\frac{h b^{3}}{12}
$$

The height and width of the beam we consider are $\mathrm{H}$ $=0.406 \mathrm{~m}, \mathrm{~B}=0.2032 \mathrm{~m}(\mathrm{H} \times \mathrm{B}=16 \times 8$ inches

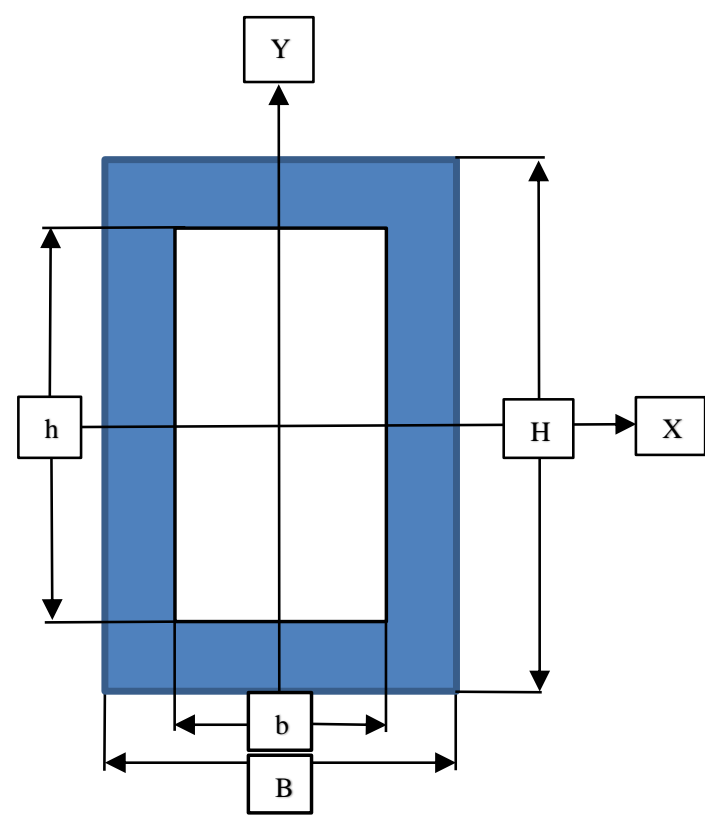

Figure 1: Model of a rectangular beam. 
steel tube). According to Rectangular Structural Steel Tube Specification the average thickness for a rectangular $16 \times 8$ steel tube is $0.005 \mathrm{~m} \mathrm{[7].}$

Now we can find the inside height $\boldsymbol{h}=0.406-0.005 * 2=\mathbf{0 . 3 9 6 m}$ and inside width $\boldsymbol{b}=$ $0.2032-0.005 * 2=\mathbf{0 . 1 9 3 2} \boldsymbol{m}$. Then

Moment of Inertia $=I_{\boldsymbol{y}}=\frac{0.406 * 0.2032^{3}}{12}-\frac{0.396 * 0.1932^{3}}{12}=\mathbf{0 . 0 0 0 0 4 5 8 9} \mathbf{m}^{\mathbf{4}}$

\section{Total LENGTH $(L)$}

Total length is the overall length of the beam under consideration. In our case it is 9.0 meter beam.

\section{UNIFORM DistribUted LOAD $(Q)$}

Uniform distributed load is a force applied over an area, denoted by $q$ which is force per unit length [2].

There are three types of load:

a) POINT LOAD.

b) TRIANGULAR LOAD

c) UNIFORMLY DISTRIBUTED LOAD (UDL) 


\section{POINT LOAD}

Point load is the load that acts over a small distance. Because of concentration over a small distance this load can be considered as acting on a point. Point load is denoted by $\mathbf{P}$ and symbol of point load is arrow heading downward $(\downarrow)[2]$ :

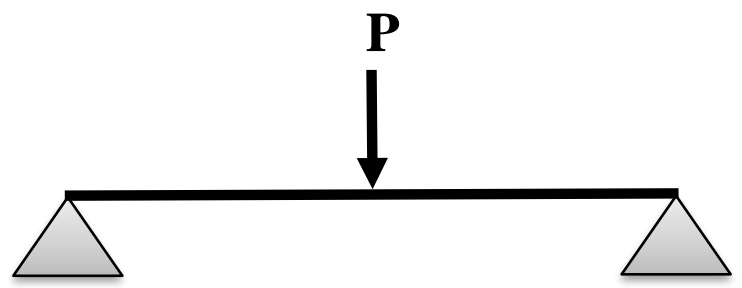

Figure 2: Example of point load.

\section{TRIANGULAR LOAD}

Triangular load is that whose magnitude is zero at one end of span and increases constantly till the 2nd end of the span. As shown in the diagram:

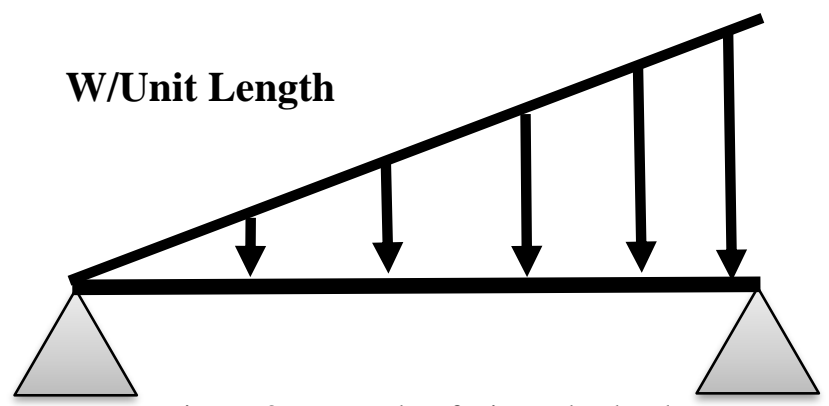

Figure 3: Example of triangular load.

UNIFORMLY DISTRIBUTED LOAD (UDL)

Uniformly distributed load is that whose magnitude remains uniform throughout the length.

\section{W/Unit Length}

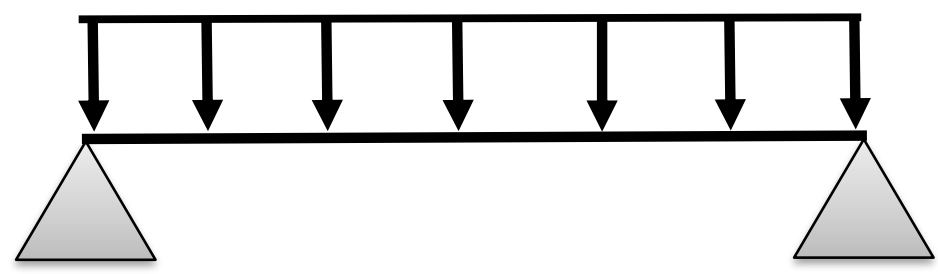

Figure 4: Example of uniformly distributed load. 
In our case, the roof is flat, snow is going to accumulate even on each part of the roof which is a

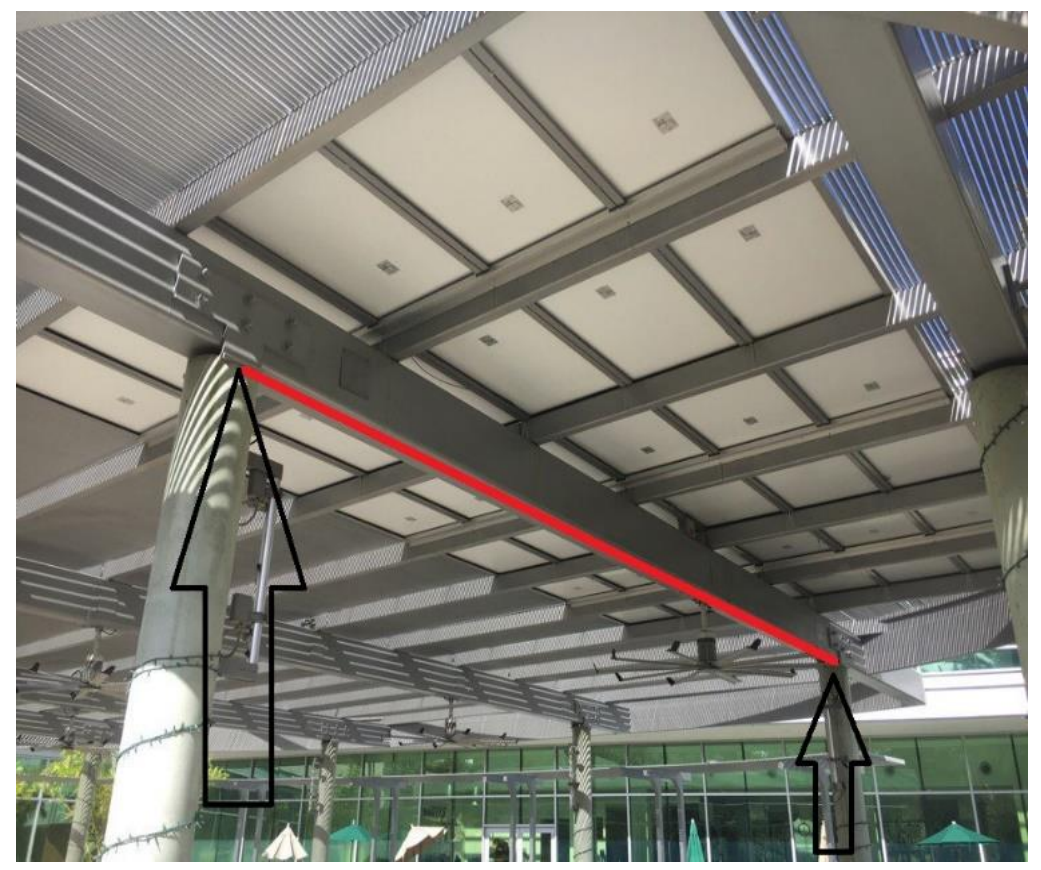

Picture 2: Photo of the rectangular $16 \times 8$ inches beam, supported on both sides. University of South Florida Marshall Student Center.

good example of Uniformly Distributed Load.

The density of the wet snow ranges between $200 \frac{\mathrm{kg}}{\mathrm{m}^{3}}$ and $600 \frac{\mathrm{kg}}{\mathrm{m}^{3}}$.

It is always important for an engineer to make all calculations for the worst case that is why we choose the snow density as $600 \frac{\mathrm{kg}}{\mathrm{m}^{3}}$.

The middle beam we make calculations for is 2 meters away from the left beam and 2 meters away from the right beam, and then $\left(\frac{2}{2}+\frac{2}{2}\right) * 9.0=18.0 \mathrm{~m}^{2}$ of the roof is significantly affecting the middle beam.

Florida's record snowfall for one day is 4.0 inches, which is equal to $0.10 \mathrm{~m}$ (March 6, 1954) [5]. Within the area of $18 \mathrm{~m}^{2}$ and such snow thickness the weight of snow is equal to $1080 \mathrm{~kg}$. Then Force acting $[$ on $]($ to $)$ the beam $=m g=1080 * 9.81=10594.8 \mathrm{~N}$ 


$$
\begin{aligned}
& \text { Uniform Distributed Load }(q)=\frac{\text { Force acting }(\text { to })[\mathrm{on}] \text { the beam }}{\text { Length of the beam }}=\frac{10594.8 \mathrm{~N}}{9.0 \mathrm{~m}} \\
& \quad=1177.2 \frac{\mathrm{N}}{\mathrm{m}}
\end{aligned}
$$

\section{MAXIMUM Deflection $(Y)$}

Maximum deflection (y) is the greatest distance the end of the beam could move up (+) or down (-) when a load of the specified magnitude is applied to the beam [4].

When we calculate the maximum deflection we must remember that the formula used for the calculation may have a slightly different view if the calculation is carried out for different types of loads, it will have a different impact on the beam. We do calculations to determine the maximum deflection of a beam when it is supported on both ends as a uniformly loading stress beam.

To get the final formula we first use the Equation of the Elastic Curve. The curvature of a plane curve at a point $\mathrm{Q}(\mathrm{x}, \mathrm{y})$ of the curve may be expressed as [4]:

$$
\frac{1}{p}=\frac{\frac{d^{2} y}{d x^{2}}}{\left[1+\left(\frac{d y}{d x}\right)^{2}\right]^{3 / 2}}
$$

where $\frac{d y}{d x}$ and $\frac{d^{2} y}{d x^{2}}$ are the first and second derivatives of the function $y(x)$ represented by that curve and $p$ is the radius of curvature. But in the case of the elastic curve of a beam the slope $\frac{d y}{d x}$ is very small, and its square is negligible: 


$$
\frac{1}{p} \approx \frac{d^{2} y}{d x^{2}}
$$

It follows that

$$
\frac{d^{2} y}{d x^{2}}=\frac{M(x)}{E I}
$$

The obtained equation is a second-order linear differential equation which is the governing differential equation for the elastic curve. Now, let us determine the equation of the elastic curve

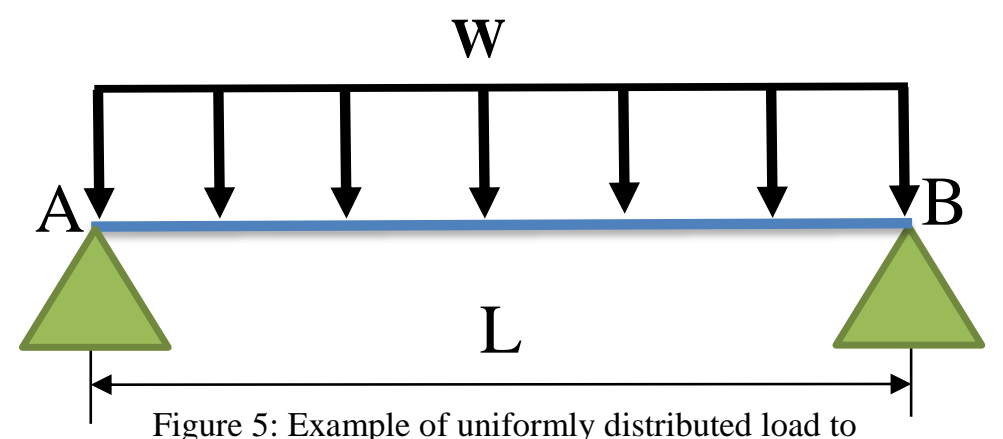

Figure 5: Example of uniformly distributed load to determine the maximum deflection of the beam.
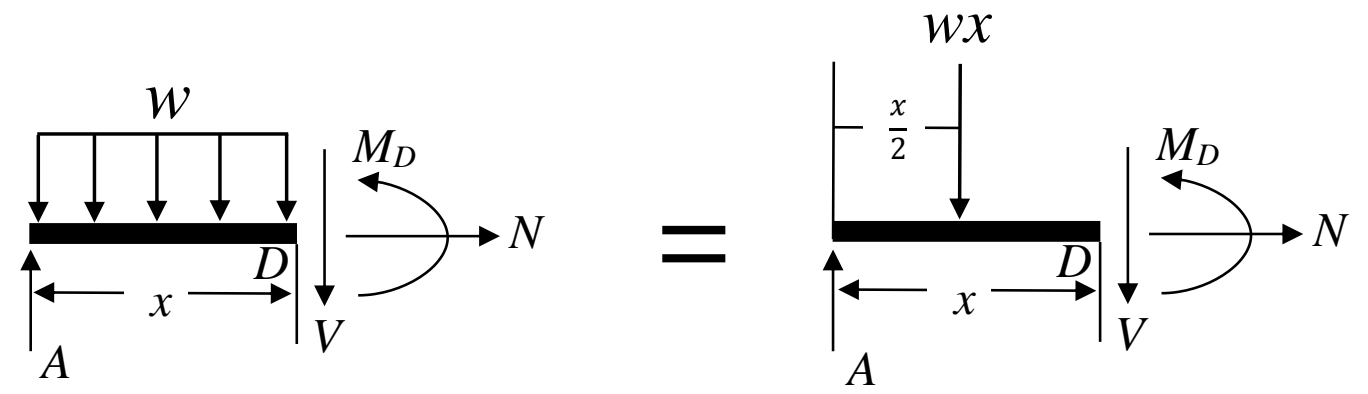

Figure 6: The free-body diagram of the portion AD of the beam.

and the maximum deflection of the beam. The simply supported prismatic beam $A B$ carries a uniformly distributed load W per unit length (Figure 5). 
Drawing the free-body diagram (Figure 6) of the portion $\mathrm{AD}$ of the beam, and taking moments about D, we find that:

$$
M=\frac{1}{2} w L x-\frac{1}{2} w x^{2}
$$

Substituting for $\mathrm{M}$ into equation (3) and multiplying both members of this equation by the constant EI, we write

$$
\begin{gathered}
E I \frac{d^{2} y}{d x^{2}}=-\frac{1}{2} w x^{2}+\frac{1}{2} w L x \\
\text { Integrating twice in } \mathrm{x}, \text { we have } \\
E I \frac{d y}{d x}=-\frac{1}{6} w x^{3}+\frac{1}{4} w L x^{2}+C_{1} \\
E I y=-\frac{1}{24} w x^{4}+\frac{1}{24} w L x^{3}+C_{1} x+C_{2}
\end{gathered}
$$

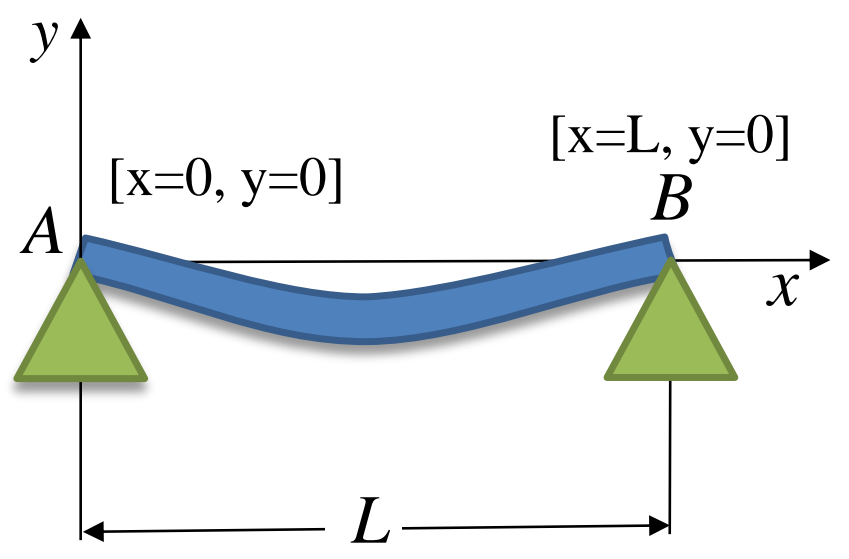

Figure 7
Observing that $\mathrm{y}=0$ at both ends of the beam (Figure 7), we first let $\mathrm{x}=0$ and $\mathrm{y}=0$ in equation (5) and obtain $\mathrm{C}_{2}=0$. We then make $\mathrm{x}=\mathrm{L}$ and $\mathrm{y}=0$ in the same equation and write:

$$
0=-\frac{1}{24} w L^{4}+\frac{1}{12} w L^{4}+C_{1} L
$$




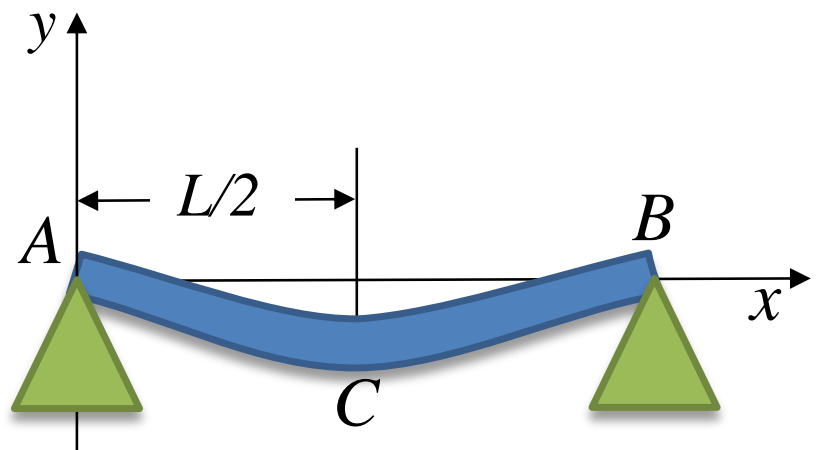

Figure 8

$$
C_{1}=-\frac{1}{24} w L^{3}
$$

Carrying the values of $\mathrm{C}_{1}$ and $\mathrm{C}_{2}$ back into equation (5), we obtain the equation of the elastic curve:

$$
\begin{gathered}
E I y=-\frac{1}{24} x^{4}+\frac{1}{12} w L x^{3}-\frac{1}{24} w L^{3} x \\
\text { Or }
\end{gathered}
$$

$$
y=\frac{w}{24 E I}\left(-x^{4}+2 L x^{3}-L^{3} x\right)
$$

Substituting into equation (4) the value obtained for $\mathrm{C}_{1}$, we check that the slope of the beam is zero for $\mathrm{x}=\mathrm{L} / 2$ and that the elastic curve has a minimum at the midpoint $\mathrm{C}$ of the beam (Figure 8) [4]. Letting $x=L / 2$ in equation (6), we have

$$
y_{c}=\frac{w}{24 E I}\left(-\frac{L^{4}}{16}+2 L \frac{L^{3}}{8}-L^{3} \frac{L}{2}\right)=-\frac{5 w L^{4}}{384 E I}
$$

The maximum deflection or, more precisely, the maximum absolute value of the deflection, is

$$
|y|_{\max }=\frac{5 w L^{4}}{384 E I}
$$

or

$$
|y|_{\max }=\frac{5 q L^{4}}{384 E I}
$$


Now let us put the known values into the maximum deflection equation:

$$
|\boldsymbol{y}|_{\max }=\frac{5 * 1177.2 \frac{\mathrm{N}}{\mathrm{m}} * 9.0^{4} \mathrm{~m}^{4}}{384 * 200000000000 \mathrm{~Pa} * 0.00004589 \mathrm{~m}^{4}}=0.01096 \mathrm{~m} \approx 1.1 \mathrm{~cm}
$$

\section{Deflection Limits}

According to AS 1170.1 Minimum design loads on structures (known as the SAA Loading Code) [3] are:

Maximum allowable deflection $=$ span $\div 300$

$$
9.0 \mathrm{~m} \div 300=0.03 \mathrm{~m}=3.0 \mathrm{~cm}
$$

A $9.0 \mathrm{~m}$ beam has a maximum allowable deflection of $3.0 \mathrm{~cm}$.

Under our conditions the maximum deflection is $1.1 \mathrm{~cm}$, which is completely allowable.

\section{DISCUSSION}

The biggest snowfall in the US for a single calendar day belongs to Georgetown, Colorado where 63 inches landed on December 4, 1913 [5]. Now let us try to imagine our stage there.

When 63 inches or 1.6 meter land, the area turns to accumulate the volume of

$$
V=18 m^{2} * 1.6 m=28.8 m^{3}
$$

It is easy for the snow to lay a long time without melting in Colorado. This causes the density increase from $60 \mathrm{~kg} / \mathrm{m}^{3}$ (fresh snow) up to $300 \mathrm{~kg} / \mathrm{m}^{3}$ which means:

$28.8 \mathrm{~m}^{3} * 300 \mathrm{~kg} / \mathrm{m}^{3}=8640 \mathrm{~kg}$ or $84758.4 \mathrm{~N}$ of force to the beam. 
In this case:

Uniform Distributed Load $(q)=\frac{\text { Force acting to the beam }}{\text { Length of the beam }}=\frac{84758.4 \mathrm{~N}}{9.0 \mathrm{~m}}=9417.6 \frac{\mathrm{N}}{\mathrm{m}}$

This leads us to Maximum deflection which is:

$|y|_{\text {max }}=\frac{5 q L^{4}}{384 E I}=\frac{5 * 9417.6 \frac{N}{m} * 9.0^{4} \mathrm{~m}^{4}}{384 * 200000000000 P a * 0.00004589 \mathrm{~m}^{4}}=\mathbf{0 . 0 8 7 6 6 ~} \mathbf{m} \approx \mathbf{8 . 8} \mathbf{c m}$

This deflection is almost 3 times more than the maximum allowable. 


\section{CONCLUSION AND RECOMMENDATIONS}

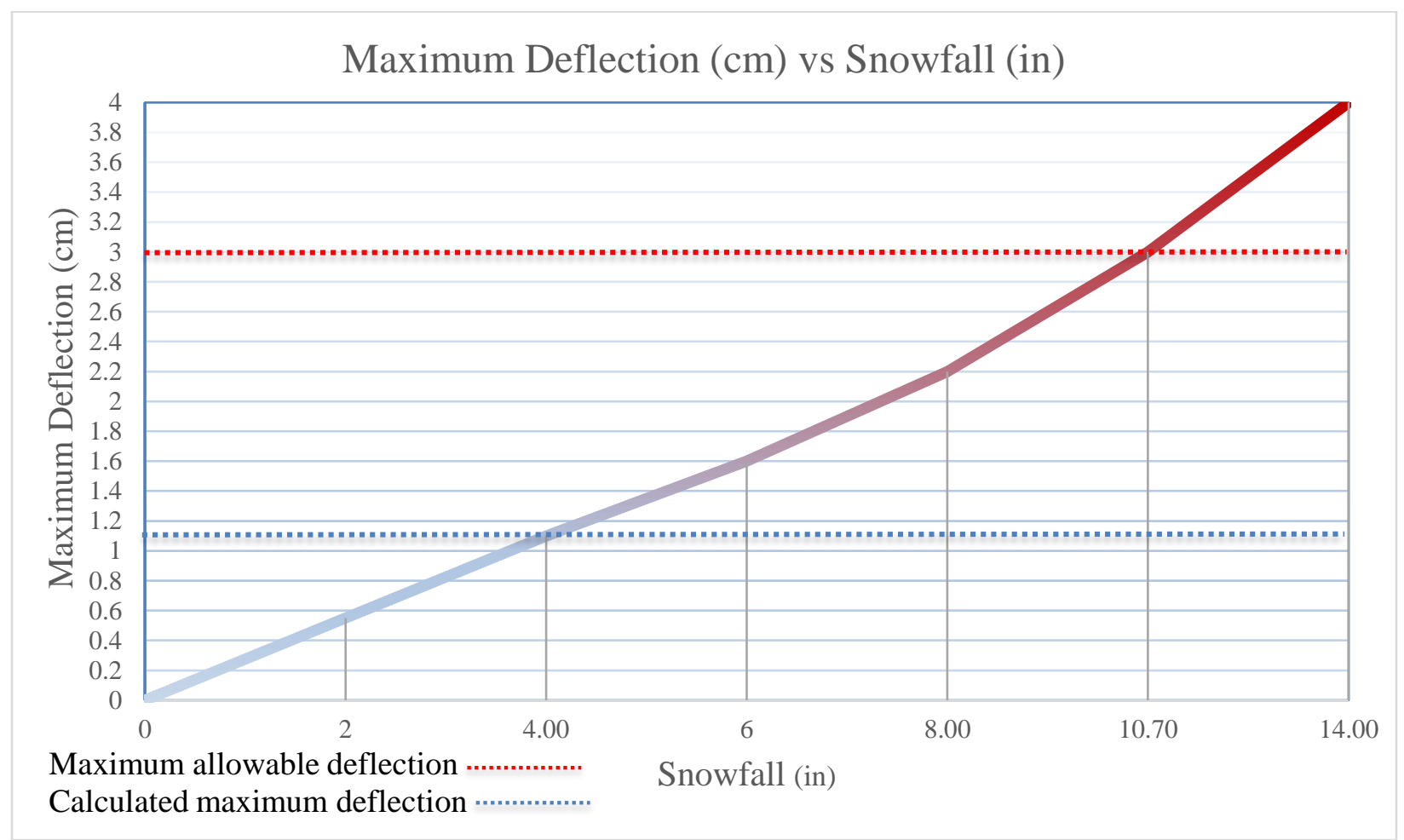

Figure 9: Graph of relation between maximum deflection in centimeters of rectangular - 16 x 8 inches beam and amount of snow in inches (snow density $600 \frac{\mathrm{kg}}{\mathrm{m}^{3}}$ ) landed on the flat $18 \mathrm{~m}^{2}$ roof.

The roof construction of the University of South Florida Marshall Student Center stage can hold all the potential Florida weather conditions, even in rare weather cases like a snowfall of March 6, 1954 when Florida experienced 4 inches of snow [5]. The maximum deflection of the beam in this case is $1.1 \mathrm{~cm}$ which is still below the maximum allowable (Figure 9), $3.0 \mathrm{~cm}$ according to AS 1170.1 Minimum design loads on structures [3].

However, for Colorado this stage construction does not apply due to the different weather conditions in Georgetown, Colorado where 63 inches of snow landed on December 4, 1913 [5]. The maximum deflection of the beam in this case is $8.8 \mathrm{~cm}$ which is almost three times more than allowable $3.0 \mathrm{~cm}$. This deflection might cause the beam destruction (Figure 10). 


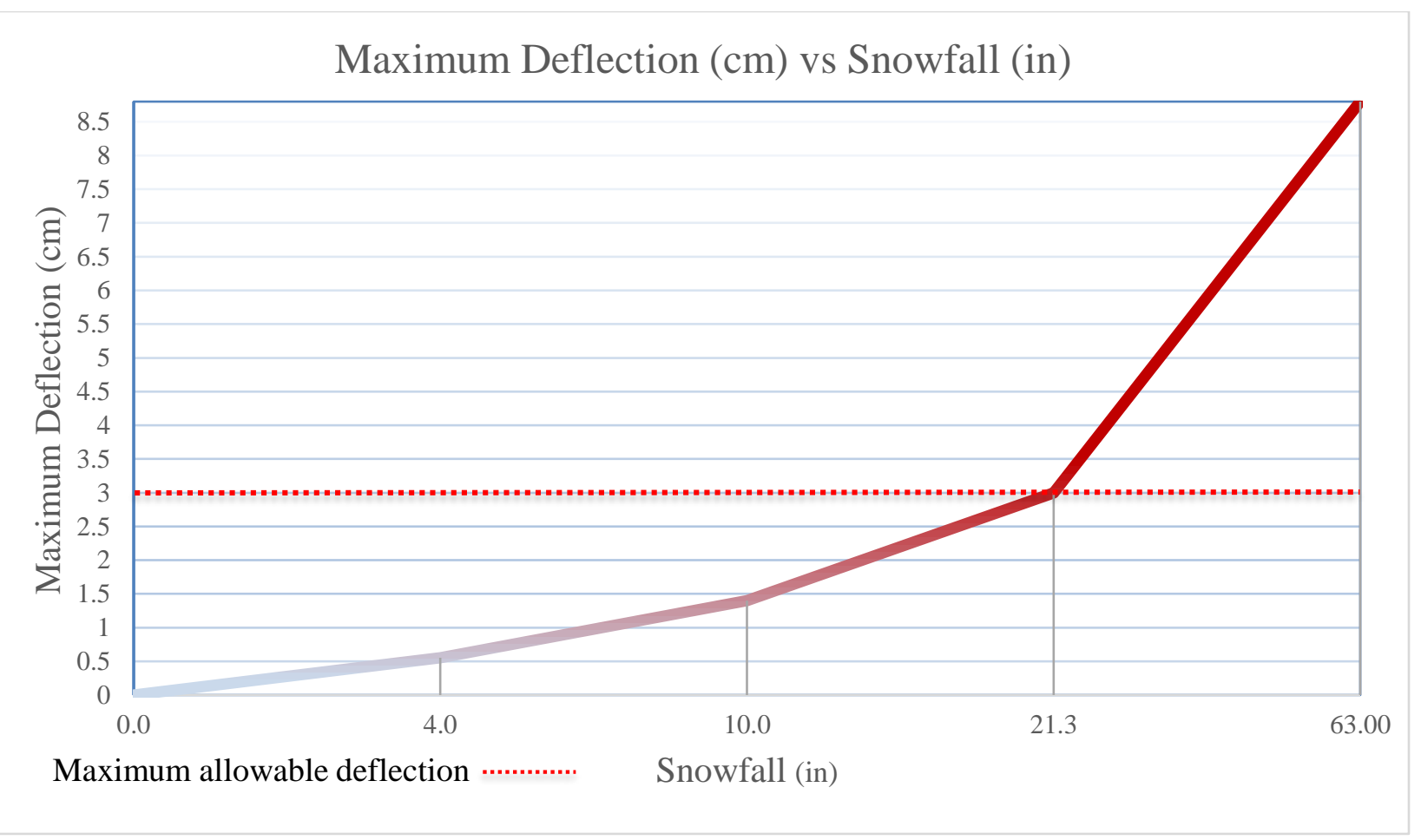

Figure 10: Graph of relation between maximum deflection in centimeters of rectangular - $16 \times 8$ beam and amount of snow in inches (snow density $300 \frac{\mathrm{kg}}{\mathrm{m}^{3}}$ ) landed on the flat $18 \mathrm{~m}^{2}$ roof in Georgetown, Colorado. 


\section{NOMENCLATURE}

\begin{tabular}{|c|c|c|}
\hline Symbol & Description & Units \\
\hline$E$ & $\begin{array}{l}\text { Young's Modulus } \\
\text { or Modulus of } \\
\text { Elasticity }\end{array}$ & $P a$ \\
\hline$\sigma$ & Stress & $\frac{N}{m^{2}}$ \\
\hline $\boldsymbol{F}$ & Force & $N$ \\
\hline$A$ & Area of object & $m^{2}$ \\
\hline$\varepsilon$ & Strain & $m / m$ \\
\hline$d L$ & $\begin{array}{l}\text { Elongation or } \\
\text { compression of } \\
\text { the object }\end{array}$ & $m$ \\
\hline$L$ & $\begin{array}{c}\text { Length of the } \\
\text { object }\end{array}$ & $m$ \\
\hline$I_{y}$ & $\begin{array}{l}\text { Moment of Inertia } \\
\text { about Y-axis }\end{array}$ & $m^{4}$ \\
\hline$d y / d x$ & First derivatives & $m$ \\
\hline$d^{2} y / d x^{2}$ & $\begin{array}{c}\text { Second } \\
\text { derivatives }\end{array}$ & $m$ \\
\hline$E I$ & Flexural rigidity & $m$ \\
\hline$q$ & $\begin{array}{c}\text { Uniform } \\
\text { Distributed Load }\end{array}$ & $N / m$ \\
\hline$C_{1}$ & $\begin{array}{l}\text { Constant of } \\
\text { integration }\end{array}$ & \\
\hline$C_{2}$ & $\begin{array}{l}\text { Constant of } \\
\text { integration }\end{array}$ & \\
\hline$y_{\max }$ & $\begin{array}{l}\text { Maximum } \\
\text { Deflection }\end{array}$ & $m$ \\
\hline $\boldsymbol{H}$ & Beam height & $\mathrm{m}$ \\
\hline $\boldsymbol{B}$ & Beam width & $\mathrm{m}$ \\
\hline $\boldsymbol{h}$ & $\begin{array}{l}\text { Beam inside } \\
\text { height }\end{array}$ & $\mathrm{m}$ \\
\hline$b$ & $\begin{array}{l}\text { Beam inside } \\
\text { width }\end{array}$ & $\mathrm{m}$ \\
\hline
\end{tabular}




\section{REFERENCES}

[1] Paterson, W. S. B. The physics of glaciers. Oxford, 1994. 8-52.

[2] Ghavami, Parviz. Mechanics of Materials. Harlingen: Springer International Publishing Switzerland, 2015. 67-73, 111-138, 143-151, 155-159.

[3] Committee BD/6, Loading on Structures. "SAA Loading Code." 20 March 1989. Saiglobal. 10 December 2016.

[4] "Deflection of Transversally Loaded Beams." Timoshenko, Stephen. Strength of Materials. Palo Alto: D. Van Nostrand Company, 1940. 134-170.

[5] Osborn, Liz. Record US Snowfalls For One Day - Current Results. 2016. 10 December 2016.

[6] The Engineering, ToolBox. Modulus of Elasticity or Young's Modulus - and Tensile Modulus for common Materials. 6 January 2012. 10 December 2016.

[7] Saginaw Pipe Co., Inc. Rectangular Structural Steel Ttube Specification. 2016. December 2016. 